\title{
How relevant is social interaction in second language learning?
}

\author{
Laura Verga ${ }^{1}$ and Sonja A. Kotz ${ }^{1,2}$ \\ Department of Neuropsychology, Research group Subcortical Contributions to Comprehension, Max Planck Institute for Human Cognitive and Brain Sciences, \\ Leipzig, Germany \\ ${ }^{2}$ School of Psychological Sciences, The University of Manchester, Manchester, UK
}

Edited by:

Srikantan S. Nagarajan, University of

California, San Francisco, USA

\section{Reviewed by:}

Mikko E. Sams, Helsinki University of Technology, Finland

Caroline A. Niziolek, University of

California, San Francisco, USA

\section{*Correspondence:}

Laura Verga, Department of

Neuropsychology, Research group

Subcortical Contributions to

Comprehension, Max Planck Institute

for Human Cognitive and Brain

Sciences, Stephanstrasse 1a, 04103

Leipzig, Germany

e-mail:verga@cbs.mpg.de
Verbal language is the most widespread mode of human communication, and an intrinsically social activity. This claim is strengthened by evidence emerging from different fields, which clearly indicates that social interaction influences human communication, and more specifically, language learning. Indeed, research conducted with infants and children shows that interaction with a caregiver is necessary to acquire language. Further evidence on the influence of sociality on language comes from social and linguistic pathologies, in which deficits in social and linguistic abilities are tightly intertwined, as is the case for Autism, for example. However, studies on adult second language (L2) learning have been mostly focused on individualistic approaches, partly because of methodological constraints, especially of imaging methods. The question as to whether social interaction should be considered as a critical factor impacting upon adult language learning still remains underspecified. Here, we review evidence in support of the view that sociality plays a significant role in communication and language learning, in an attempt to emphasize factors that could facilitate this process in adult language learning. We suggest that sociality should be considered as a potentially influential factor in adult language learning and that future studies in this domain should explicitly target this factor.

Keywords: language, learning, social interaction, communication, joint attention

\section{INTRODUCTION}

In his book "Pragmatics of human communication" (1967), the psychologist and philosopher Paul Watzlawic stated that it is impossible not to communicate (Watzlawick et al., 1967). Indeed, in his view, every behavior is a form of communication intended to convey a message from a sender to a receiver (Shannon and Weaver, 1963). The interaction between partners crucially defines a communicative intention: while a sender and a receiver do not have to be present at the same time or in the same place, there is no communication without one of the two partners. The interactive nature of this process is reflected by the word "communication", meaning "share with someone", "let someone know" (from the Latin cum — with — and munire - to bind together). However, the study of the most widespread vehicle of human communication, language, has so far suffered from an individualistic approach. Here, we review recent findings bridging social cognition and communication by highlighting evidence that points towards the necessity to consider the impact of social interaction when investigating second language (L2) learning.

\section{HUMAN COMMUNICATION AND THE ROLE OF SOCIAL INTERACTION}

Human language is one of the most complex codes used to communicate between individuals. In its verbal form it is based on a small subset of sounds that can be combined in a potentially infinite number of bigger elements (words, phrases, sentences).
The complexity of this code is further increased by the fact that human communication entails much more than the simple coding or decoding of linguistic utterances: For a communicative act to be effective, it is necessary for both the sender and receiver to understand the intentional state of a partner (Newman-Norlund et al., 2009; De Ruiter et al., 2010), an ability termed Theory of Mind (ToM) or mentalizing (Frith and Frith, 2006). The processes subtending ToM can be triggered by different contextual cues as long as they come from an agent (Frith and Frith, 2006); their function is to facilitate predictions about the others' behavior via both verbal (Carruthers, 2002) and non-verbal (Noordzij et al., 2009; Willems et al., 2010) communication. An example of the latter case is reported in severe aphasic patients: although virtually unable to express themselves verbally, these patients are able to pass tests intended to specifically tackle their residual communicative abilities; for example, they are able to engage in intention recognition with a partner in a non verbal game requiring to signal the position of a specific target on a checkerboard (Willems and Varley, 2010; Willems et al., 2011). Another example comes from normally developing infants: although they have not yet developed verbal language, they are able to use the caregiver's gaze direction as a cue to orient attention; this behavior requires a proto-mentalizing ability to infer the caregiver's intention and represents one of the first communicative acts in children (Tomasello, 1995; Tomasello and Carpenter, 2007; Csibra and Gergely, 2009; see below). In adults mentalizing processes 
are activated by cues such as the identity of the person they are interacting with. In a recent study, Newmann-Norlund and colleagues demonstrated that in a non-verbal communicative task, adult participants adapted their communicative behavior to the presumed cognitive abilities of the partner. In the employed task participants had to communicate to a partner the spatial location of a target on a checkerboard by moving a token to the position of the target; they were told that the partner could either be an adult or a child. When they were prone to believe they were interacting with a child, participants spent more time moving the cursor, thus emphasizing a crucial element of communication such as the target location (Newman-Norlund et al., 2009). When the partner is a peer, adults still adapt their behavior; in most of the cases, this adaptation is reciprocal and results in behavioral resemblance between the partners. For example, pairs of adults tend to coordinate their body postures and gaze patterns during conversation, even without being aware of it (Shockley et al., 2007, 2009), and reduce the variability of their actions to better synchronize with each other (Vesper et al., 2011, 2012). Another example is the tendency to share feelings and emotions of others, often leading to the mimicry of an observed emotion (de Vignemont and Singer, 2006; Singer, 2006). An immediate evolutionary advantage of these phenomena is to facilitate learning mechanisms based on observation and imitation (Frith and Frith, 2012). However, how do these coordinative and imitative phenomena influence language? First of all, effective communication is based on the ability to know when it is the right moment to speak. This turn taking ability relies on general coordinative rules, both on the side of motor coordination (Shockley et al., 2009), and on the side of conversation. For example, you do not want your partner to wait forever for an answer, but you also do not want to speak while he is still speaking ("minimal gap, minimal overlap" rule, Stivers et al., 2009). Furthermore, aspects of a conversation, such as the speaking rate and the similarity of words spoken in a dyad, also influence the coordinative pattern as demonstrated by Shockley et al. (2007). The authors showed that pairs of participants were maximally synchronized in their bodily movements when they were uttering the same words at the same time (Shockley et al., 2007). Even more importantly, imitative motor phenomena are influenced by the conceptual level of the conversation: for example, hand gestures in a conversation are likely to be imitated and repeated by the partners, but only if they make sense in the context of the speech (Mol et al., 2012).

Taken together, this evidence suggests that there is a twoway influence between social interaction and communication. However, the role played by social interaction has been greatly undervalued so far, especially in studies on language learning, even though this context represents a prototypical interactive communicative situation. In the following sections, we will first describe technical limitations that may have been responsible for such paucity in research; then we highlight evidence on the impact of social interaction on learning in clinical and nonclinical populations.

\section{BRAIN IMAGING IN INTERACTING INDIVIDUALS: ISSUES AND SOLUTIONS}

Probably one of the reasons why social interaction has not been considered as a factor in language learning studies until recently is the limitation that dual settings pose to imaging set-ups. Luckily, the influence of an interactive social approach has increased exponentially over the last decade (Knoblich and Sebanz, 2006, 2008; Galantucci and Sebanz, 2009; Schilbach et al., 2013), leading to an attempt to find new techniques and to create experimental situations tailored towards real-life situations often involving more than one person (Montague et al., 2002; Hasson et al., 2012). This effort has lead to the development of paradigms intended to specifically tackle social situations (Schippers et al., 2010; Anders et al., 2011), in which participants are often made to believe that they are interacting with someone. For example, pairs of participants may be required to take turns in the fMRI scanner while observing a video recording of the partner during meaningful gestural (Schippers et al., 2009, 2010; Redcay et al., 2010) or affective (Anders et al., 2011) communication, while they believe this interaction is happening in real time. These kinds of "fake" communicative situations have allowed researchers to observe in-vivo activations in brain areas involved in the ToM system. This is supported by a network encompassing the medial prefrontal cortex (mPFC), the posterior superior temporal sulcus (pSTS), the temporo-parietal junction (TPJ), and the temporal poles (TP) (Amodio and Frith, 2006; Frith and Frith, 2006; Saxe, 2006; Decety and Lamm, 2007; Newman-Norlund et al., 2007; Noordzij et al., 2009). Another system usually involved in "social" tasks is the human Mirror Neuron System (MNS). This system encompasses a fronto-parietal network of the ventral premotor cortex (vPMC), the inferior frontal gyrus (IFG), and the inferior parietal lobule (iPL) in its rostral portion (Rizzolatti and Craighero, 2004), and possibly other regions, including the dorsal premotor cortex (dPMC), the supplementary motor cortex (SMA), and the temporal lobe (Keysers and Gazzola, 2009). Important for the topic of this review, these "mirror" neurons deal with the decoding of an action goal not only when one is performing an action, but also when observing the same action being performed by someone else (Rizzolatti and Fabbri-Destro, 2008; Keysers and Gazzola, 2009). These neurons thus provide an interface between one's own motor repertoires and others' (Knoblich and Sebanz, 2006). This "goal-sharing" property supports the hypothesis that brain areas exhibiting mirror-like properties should be more active during joint action than during solitary actions (Newman-Norlund et al., 2007). Although these "fake" social interactive tasks allow this hypothesis to be indirectly tested, recent developments in neuroimaging have allowed the creation of new techniques to be applied to fMRI (Montague et al., 2002), EEG (Astolfi et al., 2010, 2011), and NIRS (Cui et al., 2012), enabling two (and sometimes more) people to be tested at the same time. These "hyper-scanning" techniques (Dumas et al., 2011) allow ecologically valid interactions to be studied in a number of tasks, which could then also be applied to interactive learning paradigms. The clear advantage is that they allow a direct comparison of processes happening in two brains at the same time, a comparison which could otherwise only be inferred. Thus, one could potentially observe both the effects of mentalizing (King-Casas et al., 2005; Astolfi et al., 2010; Saito et al., 2010; Cui et al., 2012) and of synchronization (Tognoli et al., 2007; Schippers et al., 2010) on brain activity in a realtime learning set-up. The use of hyper-scanning in these tasks demonstrates that not only the behavior of two interacting people 
is influenced by social interaction, but also their brain activation patterns. Indeed, synchronized EEG activity in frontal and central regions has been found in theta and delta oscillations of pairs of guitarists playing a melody together (Lindenberger et al., 2009); similarly, when pairs of participants are required to spontaneously imitate each others, their brain activity becomes synchronized in the alpha-mu band over right-centro-parietal regions (Dumas et al., 2010). Activity in this frequency band has been proposed to represent a neuromarker of human social coordination and, more specifically, has been linked to the human MNS (Tognoli et al., 2007). Saito et al. (2010) used fMRI hyper-scanning to scan two people at the same time while they were engaged in a real-time gaze exchange; that is to say, the pair were asked to direct one anothers' attention to an object via eye movements. The authors found that the exchange of attention via eye gaze resulted in an inter-subject synchronization of the neural activity in the right IFG (Saito et al., 2010). Mentalizing and mirror systems thus seem to be recruited in social tasks (Uddin et al., 2007; Van Overwalle, 2008; Van Overwalle and Baetens, 2009; Ciaramidaro et al., 2013), but their activity is influenced by the presence of a partner. Thus, the question arises: what happens in the case of learning a new language? A first attempt to answer this question arises from a recent study by Jeong and colleagues; the authors suggest that when words in a novel language are learnt in a social situation (but not when they are learnt from a text), elicited brain activity (in the right supramarginal gyrus) is similar to the activity elicited by words in one's mother tongue (Jeong et al., 2010). However, the social situation depicted in this study was represented by movie clips of a dialogue. Thus, the question remains: what happens in a natural (social) learning situation?

\section{LANGUAGE LEARNING AND SOCIAL INTERACTION IN CHILDREN}

As previously pointed out, the ability to socially interact emerges very early in life (Grossmann and Johnson, 2007), and is represented by a number of basic interactions that children in the first year of life are able to master, such as following the caregivers' gaze, attracting her/his attention, and responding to her/his attentional requests. This set of abilities is usually grouped under the name "joint attention", entailing an interaction between a child, the caregiver, and the focus of attention (an object) (Carpenter et al., 1998; Mundy et al., 2003; Mundy and Sigman, 2006; Mundy and Newell, 2007; Mundy and Jarrold, 2010). From a psychological point of view, the role of triadic attention ability during childhood is to create a common psychological ground shared between the infant and the caregiver, and relies on the formation of ToM in children (Tomasello, 1995). In this common space, adults act as experts and guide the children toward the relevant information that should be learnt, by using an effective signal such as eye gaze (Csibra and Gergely, 2009; De Jaegher et al., 2010). In this asymmetrical learning setting, children behavior is further facilitated by the fact that adults tend to adapt their communicative behavior by emphasizing crucial aspects of communication (for example, by spending more time on them; Newman-Norlund et al., 2009). Moreover, the interaction with the caregiver increases motivation, thus reinforcing a given behavior (Vrtička et al., 2008;
Hari and Kujala, 2009; Syal and Finlay, 2011). This asymmetrical learning setting, in which knowledge is passed from parents to offspring, is not limited to humans and can be found, for example, in many bird species that use complex vocal codes to communicate (Kuhl, 2007; Hari and Kujala, 2009; Frith and Frith, 2012). However, ToM abilities underlying human communication seem to represent a unicum in nature. Indeed, even our closer animal relatives, the chimpanzees, do not have the human ability to really "share" intentionality: as an example, chimpanzees are perfectly able to follow the gaze of an interacting human, but they do not try to start joint attention, nor do they try to infer the referent of the gaze as human children do (Tomasello and Carpenter, 2007). This human ability to share intentionality and acquired knowledge with other humans has been proposed to be at the core of the evolution of verbal language (Tomasello, 1995; Pinker, 2010). A series of experiments conducted by Kuhl and colleagues aimed to investigate this possibility and to test the impact of social interaction on phonetic discrimination in children (Kuhl et al., 2003; Kuhl, 2007). Cohorts of American infants were exposed to native speakers of Mandarin Chinese and subsequently performed a phonetic discrimination task; the exposure either occurred via direct interaction or via pre-recorded video tapes. Interestingly, infants were able to learn different Mandarin phonemes when they were exposed to them by a real person, but not when the exposure was merely via a recording (Kuhl et al., 2003). There are two plausible explanations for this effect; first, a live human may attract more attention and increase motivation, as compared to a recording. Second, a real person can provide referential information, crucial for linking words and concepts (Waxman and Gelman, 2009). In particular, Kuhl and colleagues pointed out that joint attention towards an object being named can facilitate a child's capacity for word segmentation (Kuhl et al., 2003). Similarly, results from Hirotani et al. (2009) suggest that joint attention helps to strengthen the association between a word and its referent, thus facilitating learning. These authors found that semantic integration, reflected in the N400 effect, seemed to be present when children learn new words in a joint attention condition but not in a non-joint-attention context. Although infant learning represents a particular case, vocabulary learning poses similar demands to both children-learning their first language (L1) — and to adults_-when learning a new language. Thus, factors facilitating word learning in children could potentially impact adult learners in a similar way.

\section{THE ROLE OF SOCIALITY IN SECOND LANGUAGE LEARNING}

Evidence thus accumulates to favor the view that the development of verbal language is, at least, supported by establishing common ground between a sender and a receiver. In turn, the events that take place in such common space are mostly dependent on the interaction between the partners (Mundy and Jarrold, 2010). However, a note of caution needs to be used when comparing language learning in children and in adults. Indeed, learning of a L2 can occur largely independent of the presence of another person, and is usually learnt via explicit formal training as compared to a L1, which is acquired effortlessly without explicit instructions (Abutalebi, 2008). Nevertheless, the case of word learning represents a link between language learning in infants 
and in adults. Indeed, words in a new language can be acquired incidentally (Nagy et al., 1987; Swanborn and De Glopper, 1999; Laufer and Hulstijn, 2001; Rodríguez-Fornells et al., 2009); new words encountered while reading a text can be easily learnt. In this situation an adult learner has to face the same problems as an infant, namely the indetermination of the referents: there are multiple words in a language and multiple possible referents in terms of meaning. However, how can the correct meaning be assigned to an unknown word? The easiest way to go about this problem is exemplified by associative learning, a procedure that concentrates on the statistical learning of the co-occurrence of data from speech and its context (Breitenstein et al., 2004; Whiting et al., 2007, 2008). The advantage of this procedure is that it poses low cognitive demands during training (Pulvermüller, 1999; Dobel et al., 2010) and is resistant to errors made during a phase of guessing (Carpenter et al., 2012). The underlying rationale is that once a word is heard in an utterance or seen in a sentence, a set of potential meanings can be inferred from the context, thus reducing the number of possible referents (Adelman et al., 2006). This way, novel word forms can be acquired and integrated in the lexicon relatively quickly and successfully. For instance, neural responses evoked after training are indistinguishable from those obtained in response to "old" words, as demonstrated in the disappearance or reduction of a N400 response (MestresMissé et al., 2007). The N400 component is a negative deflection starting 200-300 ms after the presentation of a word, and has been associated with semantic processing (Lau et al., 2008). Its disappearance in a learning paradigm thus possibly corresponds to establishing a link between a novel lexeme and conceptual information (Mestres-Missé et al., 2007; Dobel et al., 2010). The neural network supporting word learning involves regions of the semantic circuitry such as the left IFG (BA 45), the middle temporal gyrus (MTG, BA 21), the parahippocampal gyrus, and several subcortical structures (Mestres-Missé et al., 2008). Although, in adults, new vocabulary can be learnt independently of the presence of a partner, social interaction may increase the number of cues and referential information in much the same way as it does in infant learning (Kuhl, 2004, 2007, 2010). Indeed, the interaction between partners in conversation could lead L2 learners to focus on certain aspects of the context and certain words in speech (Yu and Ballard, 2007). The coordinative phenomena we describe above could play a role in this process, maximizing the efficiency of the conversation and consequently facilitating the focusing of attention: this proposal has been made for word learning in toddlers. Indeed, it has been shown that in toddleradult dyads, the number of new words learnt by the toddlers is proportional to the quality of the synchronization during the interaction with the caregiver (Pereira et al., 2008). Again, it is important to note that the case of word learning is not dissimilar in adults and infants, and so one may expect facilitating factors (such as the focusing of attention driven by synchronization) to play a role in word learning for both adults and children. Indeed, although it is possible to learn a new language alone, adults often learn a new language in social contexts, most commonly in a teacher-learner setting, a setting which requires interaction with a partner as well as sophisticated reading of a speaker's intentions (Bloom, 2002; Mestres-Missé et al., 2007, 2008). Thus, the necessity to consider sociality as a factor in L2 studies seems striking, as further suggested by the evidence that when new words are encoded in a social context, but not when they are learnt by translation, the pattern of activation in the retrieval phase is similar to the one observed for L1 words (Jeong et al., 2010).

\section{LEARNING AND SOCIAL COGNITION IN PATHOLOGIES}

Learning new words, or re-learning words that have been forgotten, is the goal not only for infants and L2 learners, but also for pathological populations, including, for example people suffering from autism, dementias, or aphasia. In these pathologies, the role of social interaction is becoming increasingly acknowledged as a crucial variable for therapeutic outcome success. Communicative deficits in autism spectrum disorders have been frequently attributed to higher cognitive processing impairments, and especially to ToM deficits (Baron-Cohen et al., 1985). However, more recent evidence indicates that lower level processes may also be affected. For instance, recent findings suggest that autistic children display low-level difficulties in temporal processing, including impaired timing and deficits in the perceived duration of an event, which can in turn influence the perception of relevant social cues such as eye gaze (Allman, 2011; Allman et al., 2011; Falter and Noreika, 2011; Falter et al., 2012). The fact that ToM and timing abilities may be crucial for language, even in a population who display impaired ToM, comes from the discovery that autistic children improve their language abilities after a treatment focusing on the optimization of their joint attention capacities (Kasari et al., 2008).

Similarly, social interaction plays a role in language re-learning in aphasia. A paradigmatic example of this claim comes from a specific form of therapy for severe aphasic patients based on music, namely Melodic Intonation Therapy (Norton et al., 2009). This approach uses musical and sensory stimulation in order to improve the speech production of the aphasic patient and is centered on the role of the therapist. Although the beneficial effect of the therapy has been traditionally attributed to the effect of music tout-court, recent evidence challenges this perspective and suggests that rhythm (and not necessarily melody) holds the key to understanding the impact of music therapy (Stahl et al., 2011). Considering that music therapy is therapist-centered, this result well fits a joint-action explanation: rhythm is defined by the coordinated action between a therapist and a patient. This strongly influences timing and its variability of the single individual in the interaction. Future investigations should attempt to disentangle the role played by joint action dynamics from those played by the timing of the interaction, per se.

\section{CONCLUDING REMARKS}

In conclusion, the role of social interaction in language learning has, thus far, been widely overlooked, partly because of technical constraints posed by interactive settings in imaging studies. We propose that further studies on language learning in adults should further explore the powerful impact of social interaction. This necessity comes from at least four lines of research: first, language use intended as communication is an interactive phenomenon, relying on the ability of the partners to infer the others' mental states and to coordinate with each other in successful turn- 
taking. Second, in infants, joint attention with a caregiver provides additional contextual cues driving attention and motivation that can help to disambiguate the meaning of a new word (or stimulus); analogously, contextual learning represents one of the easiest ways for late learners to acquire new words and can thus be influenced in a similar way by social interaction. Third, and related to the second, the investigation of interactive language learning resembles a natural learning situation involving a teacher and a student. Fourth, the role of sociality is starting to emerge as a valid explanatory variable in the context of word learning in pathological populations.

\section{ACKNOWLEDGMENTS}

Laura Verga has received funding from the European Community's Seventh Framework Programme under the EBRAMUS project—grant agreement no 238157.

\section{REFERENCES}

Abutalebi, J. (2008). Neural aspects of second language representation and language control. Acta Psychol. (Amst) 128, 466-478. doi: 10.1016/j. actpsy.2008.03.014

Adelman, J. S., Brown, G. D. A., and Quesada, J. F. (2006). Contextual diversity, not word frequency, determines word-naming and lexical decision times. Psychol. Sci. 17, 814-823. doi: 10.1111/j.1467-9280. 2006.01787.x

Allman, M. J. (2011). Deficits in temporal processing associated with autistic disorder. Front. Integr. Neurosci. 5:2. doi: 10.3389/fnint.2011.00002

Allman, M. J., Pelphrey, K. A., and Meck, W. H. (2011). Developmental neuroscience of time and number: implications for autism and other neurodevelopmental disabilities. Front. Integr. Neurosci. 6:7. doi: 10.3389/fnint.2012.00007

Amodio, D. M., and Frith, C. D. (2006). Meeting of minds: the medial frontal cortex and social cognition. Nat. Rev. Neurosci. 7, 268-277. doi: 10.1038/nrn1884

Anders, S., Heinzle, J., Weiskopf, N., Ethofer, T., and Haynes, J. D. (2011). Flow of affective information between communicating brains. Neuroimage 54, 439-446. doi: 10. 1016/j.neuroimage.2010.07.004

Astolfi, L., Toppi, J., De Vico Fallani, F., Vecchiato, G., Salinari, S., Mattia, D., et al. (2010). Neuroelectrical hyperscanning measures simultaneous brain activity in humans. Brain Topogr. 23, 243-256. doi: 10. 1007/s10548-010-0147-9

Astolfi, L., Toppi, J., Fallani, F. D. V., Vecchiato, G., Cincotti, F., Wilke, C. T., et al. (2011). Imaging the social brain by simultaneous hyperscanning during subject interaction. IEEE Intell. Syst. 26, 38-45. doi: 10. 1109/MIS.2011.61

Baron-Cohen, S., Leslie, A. M., and Frith, U. (1985). Does the autistic child have a "theory of mind"? Cognition 21, 37-46. doi: 10.1016/00100277(85)90022-8

Bloom, P. (2002). Mindreading, communication and the learning of names for things. Mind Lang.
17, 37-54. doi: 10.1111/1468-0017. 00188

Breitenstein, C., Kamping, S., Jansen, A., Schomacher, M., and Knecht, S. (2004). Word learning can be achieved without feedback: implications for aphasia therapy. Restor. Neurol. Neurosci. 22, 445-458.

Carpenter, M., Nagell, K., Tomasello, M., Butterworth, G., and Moore, C. (1998). Social cognition, joint attention, and communicative competence from 9 to 15 months of age. Monogr. Soc. Res. Child Dev. 63, 1174. doi: 10.2307/1166214

Carpenter, S. K., Sachs, R. E., Martin, B., Schmidt, K., and Looft, R. (2012). Learning new vocabulary in German: the effects of inferring word meanings, type of feedback, and time of test. Psychon. Bull. Rev. 19, 81-86. doi: 10.3758/s13423-0110185-7

Carruthers, P. (2002). The cognitive functions of language. Behav. Brain Sci. 25, 657-674.

Ciaramidaro, A., Becchio, C., Colle, L., Bara, B. G., and Walter, H. (2013). Do you mean me? Communicative intentions recruit the mirror and the mentalizing system. Soc. Cogn. Affect. Neurosci. doi: 10. 1093/scan/nst062. [Epub ahead of print].

Csibra, G., and Gergely, G. (2009). Natural pedagogy. Trends Cogn. Sci. 13, 148-153. doi: 10.1016/j.tics.2009.01. 005

Cui, X., Bryant, D. M., and Reiss, A. L. (2012). NIRS-based hyperscanning reveals increased interpersonal coherence in superior frontal cortex during cooperation. Neuroimage 59, 2430-2437. doi: 10.1016/j. neuroimage.2011.09.003

De Jaegher, H., Di Paolo, E., and Gallagher, S. (2010). Can social interaction constitute social cognition? Trends Cogn. Sci. 14, 441-447. doi: 10.1016/j.tics.2010.06.009

De Ruiter, J. P., Noordzij, M. L., Newman-Norlund, S., NewmanNorlund, R., Hagoort, P., Levinson, S. C., et al. (2010). Exploring the cognitive infrastructure of communication. Interact. Stud. 11, 51-77. doi: 10.1075/is.11.1.05rui de Vignemont, F., and Singer, T. (2006). The empathic brain: how, when and why? Trends Cogn. Sci. 10, 435-441. doi: 10.1016/j.tics.2006.08.008

Decety, J., and Lamm, C. (2007). The role of the right temporoparietal junction in social interaction: how low-level computational processes contribute to meta-cognition. Neuroscientist 13, 580-593. doi: 10 . 1177/1073858407304654

Dobel, C., Junghöfer, M., Breitenstein, C., Klauke, B., Knecht, S., Pantev, C. et al. (2010). New names for known things: on the association of novel word forms with existing semantic information. J. Cogn. Neurosci. 22, 1251-1261. doi: 10.1162/jocn.2009. 21297

Dumas, G., Lachat, F., Martinerie, J., Nadel, J., and George, N. (2011). From social behaviour to brain synchronization: review and perspectives in hyperscanning. IRBM 32, 48-53. doi: 10.1016/j.irbm.2011.01. 002

Dumas, G., Nadel, J., Soussignan, R., Martinerie, J., and Garnero, L. (2010). Inter-brain synchronization during social interaction. PLoS One 5:e12166. doi: 10.1371/journal. pone.0012166

Falter, C. M., and Noreika, V. (2011). Interval timing deficits and abnormal cognitive development. Front. Integr. Neurosci. 5:26. doi: 10. 3389/fnint.2011.00026

Falter, C. M., Noreika, V., Wearden, J. H., and Bailey, A. J. (2012). More consistent, yet less sensitive: interval timing in autism spectrum disorders. Q. J. Exp. Psychol. (Hove). 65, 2093-2107. doi: 10.1080/17470218. 2012.690770

Frith, C. D., and Frith, U. (2006). The neural basis of mentalizing. Neuron 50, 531-534. doi: 10.1016/j.neuron. 2006.05.001

Frith, C. D., and Frith, U. (2012) Mechanisms of social cognition. Annu. Rev. Psychol. 63, 287-313. doi: $\quad 10.1146 /$ annurev-psych120710-100449

Galantucci, B., and Sebanz, N. (2009). Joint action: current perspectives. Top. Cogn. Sci. 1, 255-259. doi: 10. 1111/j.1756-8765.2009.01017.x
Grossmann, T., and Johnson, M. H. (2007). The development of the social brain in human infancy. Eur. J. Neurosci. 25, 909-919. doi: 10. 1111/j.1460-9568.2007.05379.x

Hari, R., and Kujala, M. V. (2009). Brain basis of human social interaction: from concepts to brain imaging. Physiol. Rev. 89, 453-479. doi: 10.1152/physrev.00041.2007

Hasson, U., Ghazanfar, A. A., Galantucci, B., Garrod, S., and Keysers, C. (2012). Brain-to-brain coupling: a mechanism for creating and sharing a social world. Trends Cogn. Sci. 16, 114-121. doi: 10.1016/j.tics.2011.12. 007

Hirotani, M., Stets, M., Striano, T., and Friederici, A. D. (2009). Joint attention helps infants learn new words: event-related potential evidence. Neuroreport 20, 600-605. doi: 10.1097/wnr. 0b013e32832a0a7c

Jeong, H., Sugiura, M., Sassa, Y., Wakusawa, K., Horie, K., Sato, S., et al. (2010). Learning second language vocabulary: neural dissociation of situation-based learning and text-based learning. Neuroimage 50, 802-809. doi: 10.1016/j. neuroimage.2009.12.038

Kasari, C., Paparella, T., Freeman, S., and Jahromi, L. B. (2008). Language outcome in autism: randomized comparison of joint attention and play interventions. J. Consult. Clin. Psychol. 76, 125-137. doi: 10. 1037/0022-006x.76.1.125

Keysers, C., and Gazzola, V. (2009). Expanding the mirror: vicarious activity for actions, emotions, and sensations. Curr. Opin. Neurobiol. 19, 666-671. doi: 10.3389/fnint. 2010.00127

King-Casas, B., Tomlin, D., Anen, C., Camerer, C. F., Quartz, S. R., and Montague, P. R. (2005). Getting to know you: reputation and trust in a two-person economic exchange. Science 308, 78-83. doi: 10.1126/science. 1108062

Knoblich, G., and Sebanz, N. (2006). The social nature of perception and action. Curr. Dir. Psychol. Sci. 15, 99-104. doi: 10.1111/j.0963-7214. 2006.00415.x 
Knoblich, G., and Sebanz, N. (2008). Evolving intentions for social interaction: from entrainment to joint action. Philos. Trans. R. Soc. Lond. B Biol. Sci. 363, 2021-2031. doi: 10. 1098/rstb.2008.0006

Kuhl, P. K. (2004). Early language acquisition: cracking the speech code. Nat. Rev. Neurosci. 5, 831-843. doi: 10.1038/ nrn 1533

Kuhl, P. K. (2007). Is speech learning "gated" by the social brain? Dev. Sci. 10, 110-120. doi: 10.1111/j.14677687.2007.00572.x

Kuhl, P. K. (2010). Brain mechanisms in early language acquisition. Neuron 67, 713-727. doi: 10.1016/j.neuron. 2010.08.038

Kuhl, P. K., Tsao, F. M., and Liu, H. M. (2003). Foreign-language experience in infancy: effects of short-term exposure and social interaction on phonetic learning. Proc. Natl. Acad. Sci. U S A 100, 9096-9101. doi: 10. $1073 /$ pnas. 1532872100

Lau, E. F., Phillips, C., and Poeppel, D. (2008). A cortical network for semantics: (de)constructing the N400. Nat. Rev. Neurosci. 9, 920933. doi: 10.1038/nrn2532

Laufer, B., and Hulstijn, J. (2001). Incidental vocabulary acquisition in a second language: the construct of task-induced involvement. Appl. Linguist. 22, 1-26. doi: 10. 1093/applin/22.1.1

Lindenberger, U., Li, S. C., Gruber, W., and Müller, V. (2009). Brains swinging in concert: cortical phase synchronization while playing guitar. BMC Neurosci. 10:22. doi: 10. 1186/1471-2202-10-22

Mestres-Missé, A., Càmara, E., Rodriguez-Fornells, A., Rotte, M., and Münte, T. F. (2008). Functional neuroanatomy of meaning acquisition from context. J. Cogn. Neurosci. 20, 2153-2166. doi: 10.1162/jocn.2008.20150

Mestres-Missé, A., Rodriguez-Fornells, A., and Münte, T. F. (2007). Watching the brain during meaning acquisition. Cereb. Cortex 17, 1858-1866. doi: 10.1093/cercor/bhl094

Mol, L., Krahmer, E., Maes, A., and Swerts, M. (2012). Adaptation in gesture: converging hands or converging minds? J. Mem. Lang. 66, 249-264. doi: 10.1016/j.jml.2011.07. 004

Montague, P. R., Berns, G. S., Cohen, J. D., McClure, S. M., Pagnoni, G., Dhamala, M., et al. (2002). Hyperscanning: simultaneous fMRI during linked social interactions. $\mathrm{Neu}$ roimage 16, 1159-1164. doi: 10 . 1006/nimg.2002.1150
Mundy, P., Fox, N., and Card, J. (2003). EEG coherence, joint attention and language development in the second year. Dev. Sci. 6, 48-54. doi: 10. 1111/1467-7687.00253

Mundy, P., and Jarrold, W. (2010). Infant joint attention, neural networks and social cognition. Neural Netw. 23, 985-997. doi: 10.1016/j. neunet.2010.08.009

Mundy, P., and Newell, L. (2007). Attention, joint attention, and social cognition. Curr. Dir. Psychol. Sci. 16, 269-274.

Mundy, P., and Sigman, M. (2006). "Joint attention, social competence and developmental psychopathology," in Developmental Psychopathology, Second Edition, Volume One: Theory and Methods, eds D. Cicchetti and D. J. Cohen (Hoboken, NJ: Wiley), 293-332.

Nagy, W. E., Anderson, R. C., and Herman, P. A. (1987). Learning word meanings from context during normal reading. Am. Educ. Res. J. 24, 237-270. doi: 10. 3102/00028312024002237

Newman-Norlund, R. D., Noordzij, M. L., Meulenbroek, R. G. J., and Bekkering, H. (2007). Exploring the brain basis of joint action: coordination of actions, goals and intentions. Soc. Neurosci. 2, 48-65. doi: 10.1080/17470910701224623

Newman-Norlund, S. E., Noordzij, M. L., Newman-Norlund, R. D., Volman, I. A. C., Ruiter, J. P. Hagoort, P., et al. (2009). Recipient design in tacit communication. Cognition 111, 46-54. doi: 10.1016/j. cognition.2008.12.004

Noordzij, M. L., Newman-Norlund, S. E., De Ruiter, J. P., Hagoort, P., Levinson, S. C., and Toni, I. (2009). Brain mechanisms underlying human communication. Front. Hum. Neurosci. 3:14. doi: 10. 3389/neuro.09.014.2009

Norton, A., Zipse, L., Marchina, S., and Schlaug, G. (2009). Melodic intonation therapy. Ann. N Y Acad. Sci. 1169, 431-436. doi: 10.1111/j.17496632.2009.04859.x

Pereira, A. F., Smith, L. B., and Yu, C. (2008). Social coordination in toddler's word learning: interacting systems of perception and action. Conn. Sci. 20, 73-89. doi: 10. 1080/09540090802091891

Pinker, S. (2010). The cognitive niche: coevolution of intelligence, sociality, and language. Proc. Natl. Acad. Sci. U S A 107, 8993-8999. doi: 10. 1073/pnas.0914630107

Pulvermüller, F. (1999). Words in the brain's language. Behav. Brain Sci. 22, 253-279.
Redcay, E., Dodell-Feder, D., Pearrow, M. J., Mavros, P. L., Kleiner, M., Gabrieli, J. D. E., et al. (2010). Live face-to-face interaction during fMRI: a new tool for social cognitive neuroscience. Neuroimage 50, 1639-1647. doi: 10.1016/j. neuroimage.2010.01.052

Rizzolatti, G., and Craighero, L. (2004). The mirror-neuron system. Annu. Rev. Neurosci. 27, 169-192. doi: 10.1146/annurev.neuro.27.070203. 144230

Rizzolatti, G., and Fabbri-Destro, M. (2008). The mirror system and its role in social cognition. Curr. Opin. Neurobiol. 18, 179-184. doi: 10 1016/j.conb.2008.08.001

Rodríguez-Fornells, A., Cunillera, T. Mestres-Missé, A., and de DiegoBalaguer, R. (2009). Neurophysiological mechanisms involved in language learning in adults. Philos. Trans. R. Soc. Lond. B Biol. Sci. 364, 3711-3735. doi: 10.1098/rstb.2009. 0130

Saito, D. N., Tanabe, H. C., Izuma, K., Hayashi, M. J., Morito, Y., Komeda, H., et al. (2010). "Stay tuned": inter-individual neural synchronization during mutual gaze and joint attention. Front. Integr. Neurosci. 4:127. doi: 10.1017/ S0140525X12000660

Saxe, R. (2006). Uniquely human social cognition. Curr. Opin. Neurobiol. 16, 235-239. doi: 10.1016/j.conb.2006. 03.001

Schilbach, L., Timmermans, B., Reddy, V., Costall, A., Bente, G., Schlicht, T., et al. (2013). Toward a secondperson neuroscience. Behav. Brain Sci. 36, 393-414. doi: 10.1017/ S0140525X12000660.

Schippers, M. B., Gazzola, V., Goebel, R., and Keysers, C. (2009). Playing charades in the fMRI: are mirror and/or mentalizing areas involved in gestural communication? PLoS One 4:e6801. doi: 10.1371/journal.pone. 0006801

Schippers, M. B., Roebroeck, A., Renken, R., Nanetti, L., and Keysers, C. (2010). Mapping the information flow from one brain to another during gestural communication. Proc. Natl. Acad. Sci. U S A 107, 9388-9393. doi: 10.1073/pnas. 1001791107

Shannon, C. E., and Weaver, W. (1963). The Mathematical Theory of Communication. Urbana, IL: University of Illinois press.

Shockley, K., Baker, A. A., Richardson, M. J., and Fowler, C. A. (2007). Articulatory constraints on interpersonal postural coordination. J. Exp. Psychol. Hum. Percept. Perform.
33, 201-208. doi: 10.1037/0096 1523.33.1.201

Shockley, K., Richardson, D. C., and Dale, R. (2009). Conversation and coordinative structures. Top. Cogn. Sci. 1, 305-319. doi: 10.1111/j.17568765.2009.01021.x

Singer, T. (2006). The neuronal basis and ontogeny of empathy and mind reading: review of the literature and implications for future research. Neurosci. Biobehav. Rev. 30, 855863. doi: 10.1016/j.neubiorev.2006. 06.011

Stahl, B., Kotz, S. A., Henseler, I., Turner, R., and Geyer, S. (2011). Rhythm in disguise: why singing may not hold the key to recovery from aphasia. Brain 134, 3083-3093. doi: 10.1093/brain/ awr 240

Stivers, T., Enfield, N. J., Brown, P., Englert, C., Hayashi, M., Heinemann, T., et al. (2009). Universals and cultural variation in turn-taking in conversation. Proc. Natl. Acad. Sci. US A 106, 10587-10592. doi: 10. 1073/pnas.0903616106

Swanborn, M. S. L., and De Glopper, K. (1999). Incidental word learning while reading: a meta-analysis. Rev. Educ. Res. 69, 261-285. doi: 10. 3102/00346543069003261

Syal, S., and Finlay, B. L. (2011). Thinking outside the cortex: social motivation in the evolution and development of language. Dev. Sci. 14, 417430. doi: 10.1111/j.1467-7687.2010. 00997.x

Tognoli, E., Lagarde, J., DeGuzman, G. C., and Kelso, J. (2007). The phi complex as a neuromarker of human social coordination. Proc. Natl. Acad. Sci. U S A 104, 8190-8195. doi: 10.1073/pnas. 0611453104

Tomasello, M. (1995). "Joint attention as social cognition," in Joint Attention: Its Origins and Role in Development, eds C. Moore and P. J. Dunham (Hillsdale, NJ, England: Lawrence Erlbaum Associates, Inc), 103-130.

Tomasello, M., and Carpenter, M. (2007). Shared intentionality. Dev. Sci. 10, 121-125. doi: 10.1111/j. 1467-7687.2007.00573.x

Uddin, L. Q., Iacoboni, M., Lange, C., and Keenan, J. P. (2007). The self and social cognition: the role of cortical midline structures and mirror neurons. Trends Cogn. Sci. 11, 153-157. doi: 10.1016/j.tics.2007. 01.001

Van Overwalle, F. (2008). Social cognition and the brain: a meta-analysis. Hum. Brain Mapp. 30, 829-858. doi: 10.1002/hbm.20547 
Van Overwalle, F., and Baetens, K. (2009). Understanding others' actions and goals by mirror and mentalizing systems: a metaanalysis. Neuroimage 48, 564584. doi: 10.1016/j.neuroimage. 2009.06.009

Vesper, C., van der Wel, R. P. R. D., Knoblich, G., and Sebanz, N. (2011). Making oneself predictable: reduced temporal variability facilitates joint action coordination. Exp. Brain Res. 211, 517-530. doi: 10. 1007/s00221-011-2706-Z

Vesper, C., van der Wel, R. P. R. D., Knoblich, G., and Sebanz, N. (2012). Are you ready to jump? Predictive mechanisms in interpersonal coordination. Exp. Brain Res. 211, 517-530.

Vrtička, P., Andersson, F., Grandjean, D., Sander, D., and Vuilleumier, P. (2008). Individual attachment style modulates human amygdala and striatum activation during social appraisal. PLoS One 3:e2868. doi: 10. 1371/journal.pone.0002868
Watzlawick, P., Bavelas, J. B., and Jackson, D. D. (1967). Pragmatics of Human Communication: A Study of Interactional Patterns, Pathologies, and Paradoxes. New York: W.W. Norton and Company.

Waxman, S. R., and Gelman, S. A. (2009). Early word-learning entails reference, not merely associations. Trends Cogn. Sci. 13, 258-263. doi: 10.1016/j.tics.2009.03.006

Whiting, E., Chenery, H., Chalk, J., Darnell, R., and Copland, D. (2007). Dexamphetamine enhances explicit new word learning for novel objects. Int. J. Neuropsychopharmacol. 10, 805-816. doi: 10. 1017/S1461145706007516

Whiting, E., Chenery, H. J., Chalk, J., Darnell, R., and Copland, D. A. (2008). The explicit learning of new names for known objects is improved by dexamphetamine. Brain Lang. 104, 254-261. doi: 10. 1016/j.bandl.2007.03.003

Willems, R. M., Benn, Y., Hagoort, P., Toni, I., and Varley, R. (2011).
Communicating without a functioning language system: implications for the role of language in mentalizing. Neuropsychologia 49, 3130-3135. doi: 10.1016/j. neuropsychologia.2011.07.023

Willems, R. M., de Boer, M., de Ruiter, J. P., Noordzij, M. L., Hagoort, P., and Toni, I. (2010). A dissociation between linguistic and communicative abilities in the human brain. Psychol. Sci. 21, 8-14. doi: 10. 1177/0956797609355563

Willems, R. M., and Varley, R. (2010). Neural insights into the relation between language and communication. Front. Hum. Neurosci. 4:203. doi: 10.3389/fnhum.2010.00203

Yu, C., and Ballard, D. H. (2007). A unified model of early word learning: integrating statistical and social cues. Neurocomputing 70, 2149 2165. doi: 10.1016/j.neucom.2006. 01.034

Conflict of Interest Statement: The authors declare that the research was conducted in the absence of any commercial or financial relationships that could be construed as a potential conflict of interest.

Received: 20 December 2012; accepted: 20 August 2013; published online: 03 September 2013.

Citation: Verga L and Kotz SA (2013) How relevant is social interaction in second language learning? Front. Hum. Neurosci. 7:550. doi 10.3389/fnhum.2013.00550

This article was submitted to the journal Frontiers in Human Neuroscience.

Copyright (c) 2013 Verga and Kotz. This is an open-access article distributed under the terms of the Creative Commons Attribution License (CC BY). The use, distribution or reproduction in other forums is permitted, provided the original author(s) or licensor are credited and that the original publication in this journal is cited, in accordance with accepted academic practice. No use, distribution or reproduction is permitted which does not comply with these terms. 